I N F ORM A I I A

Jurnal Informatika, Manajemen dan Komputer, Vol. 12 No. 1, Mei 2020

elSSN : 2580-3042

pISSN : 1979-0694

\title{
PENERAPAN E-DISCUSSION PADA SMA NEGERI 1 TANAH MERAH BERBASIS WEB
}

\author{
Willyansah \\ Akademi Manajemen Informatika \& Komputer (AMIK) Tri Dharma Pekanbaru \\ Jalan Jendral Sudirman No. 68, Pekanbaru - Riau \\ e-mail :wilyerta@gmail.com
}

\begin{abstract}
ABSTRAK
Pemanfaatan computer dalam kehidupan masyarakat semakin berkembang. E-Diskusi atara guru dan siswa adalah suatu media tanya jawab berbasis online yang digunakan untuk mempermudah guru dan siswa untuk saling berkomunikasi dimana guru dan siswa dapat berkomunikasi tanpa ada batas ruang dan waktu dengan adanya E-Diskusi guru dan siswa dapat bertukar informasi baik dengan cara mengupload file, download, melihat data guru maupun siswa, dan juga bisa melaukan proses Tanya jawab ataupun membahas sesuatu seputar sekolah. Dalam penerapan E-Diskusi dapat meningkatkan mutu peambelajaran di SMA Negeri 1 Tanah Merah, dengan meningkatnya mutu pembelajaran tersebut maka akan menghasilkan siswa yang mandiri dan berkualitas. Dengan adanya E-Diskusi proses pertukaran informasi menjadi lebih efisien dan efektif.
\end{abstract}

Kata Kunci : Komputer, Media Diskusi, E-dikusi

\begin{abstract}
Utilization of computers in society is growing. E-discussion only between teachers and students is a media question and answer based online used to facilitate teachers and students to communicate with each other where teachers and students can communicate with no limits of space and time with the E-Discussion of teachers and students can exchange information either by means upload, download, view data teachers and students, and also can melaukan process of question and answer or discuss anything about the school. In the implementation of E-Discussion can improve the quality of learning in Sma Negeri 1 Tanah Merah, with the increase in the quality of learning that it will produce an independent and qualified students. EDiscussion with the information exchange process becomes more efficient and effective.
\end{abstract}

Keyword: Computer, Medium of discussion, E-discussion

\section{PENDAHULUAN}

Pemanfaatan computer dalam kehidupan masyarakat semakin berkembang. Jika dulu orang memanfaatkan computer sebatas alat pengolah data, maka sekarang dengan menggunakan computer dan didukung oleh kecanggihan teknologi maka computer memungkinkan sebagai alat penyebar informasi di kalangan masyarakat. Informasiinformasi terkini dapat disebarluaskan tidak terbatas ruang dan waktu.

Salah satu hasil dari kemajuan teknologi informasi adalah dengan adanya pembuatan ediscussion yang digunakan sebagai media diskusi, pembelajaran, tukar pikiran, media informasi dan banyak hal lain yang dapat dimanfaatkan . Ediscussion merupakan bagian dari suatu situs web yang memungkinkan pengguna untuk memulai suatu topic dan mendiskusikannya dengan yang lain. Secara umum, e-discussion memungkinkan webmaster untuk mendefenisikan forum-forum yang merupakan tempat bagi pengguna untuk posting topic (thread). Pengguna yang lain dapat memberikan tanggapan terhadap topic tersebut atau membuat topic baru sesuai keinginannya.

Sma Negeri 1 Tanah Merah merupakan sekolah menegah atas dimana terdapat berbagai jurusan seperti IPA,IPS dan Bahasa Indonesia. Dengan demikian guru dan siswa ataupun siswa yang berbeda jurusan,kelas, maupun tingkat dalam sekolah dapat berkomunikasi dengan bebas sesuai dengn kategori yang di pilih. Guru dan siswapun dapat melakukan proses tanya jawab sehingga dapat memperluas wawasan siswa baik di dalam sekolah maupun di luar sekolah. Oleh karena itu di butuhkan E-DISSCUSION yang menyajikan wadah tanya 
IN F ORM A I K

Jurnal Informatika, Manajemen dan Komputer, Vol. 12 No. 1, Mei 2020

elSSN : 2580-3042

pISSN : 1979-0694

jawab dan pertukaran informasi sehingga bisa memberikan pengetahuan baru dan dapat menjembatani proses komunikasi dan berbagi pengetahuan antara siswa Sma Negeri 1 Tanah Merah.

\section{a. Tujuan Penelitian}

Adapun tujuan penelitian ini adalah sebagai berikut :

Dengan adanya E-Discussion memudahkan guru memberikan modul pelajaran, video tutorial pembelajaran serta serta memperlancar komunikasi antar guru dan siswa pada Sma Negeri 1 Tanah Merah dalam sebuah E-Discussion.

\section{b. Tinjauan Pustaka}

Dalam suatu penetian diperlukan dukungan hasil-hasil penetian yang telah ada sebelumnya yang berkiatan dengan penetian tersebut.

Dea Diki Hamiden (2017) dalam jurnal Pembangunan Aplikasi E-Learning Berbasis Web Di Sma Bpi 1 Bandung di dapat hasil bahwa guru dan siswa dapat lebih mudah berkomunikasi, tanpa harus bertatap muka dalam kelas.

sama halnya dari Penelitian Abdullah Muammar (2016) tentang Pengembangan E-Learning Berbasis Web Di Jurusan Pendidikan Biologi Uin Raden Bandar Lampung, penggunaan internet dalam bidang sekolah sangat membantu dalam monitoring, evaluasi serta peningkatan kerja sama siswa dengan guru.

\section{METODOLOGI PENELITIAN}

Proses pengembangan sistem mempunyai beberapa tahapan mulai dari sistem itu direncanakan sampai dengan sistem tersebut diterapkan, dioperasikan, dan dipelihara. Perhatikan gambar 2.1 berikut :

1. Perencanaan Sistem

Pada tahapan ini dibentuk struktur kerja strategis yang luas, pandangan sistem informasi baru yang jelas akan memenuhi kebutuhan-kebutuhan pemakai informasi.

2. Analisa Sistem

Pada tahapan ini dilakukan proses penilaian, identifikasi dan evaluasi komponen dan hubungan timbale balik yang terkait dalam pengembangan sistem, definisi masalah, tujuan, kebutuhan, prioritas dan kendala sistem, ditambah identifikasi biaya, keuntungan.

3. Desain Sistem Secara Umum dan Detail

Tahapan ini dibentuk alternative perancangan konseptual untuk perluasan pandangan kebutuhan pemakai (berdasarkan umur, status, profesi, gender pengguna).

4. Seleksi Sistem 
IN F ORM T I K A

Jurnal Informatika, Manajemen dan Komputer, Vol. 12 No. 1, Mei 2020

eISSN : 2580-3042

pISSN : 1979-0694

\section{HASIL DAN PEMBAHASAN}

E-Discussion memberikan kemudahan kepada guru dalam menjelaskan materi-materi mata pelajaran kepada siswa, karena e-disscussion tidak hanya sekedar bahan ajar berupa text namun juga video tutorial yang sudah di upload dan di download oleh siswa di dalam E-Discussion. Dengan adanya e-discussion ini, siswa bisa kapan pun untuk menikmati mata pelajaran serta bahan ajar lain tanpa harus di damping oleh guru. Sistem Tanya jawab di dalam E-Discussion langsung di jawab oleh guru dan siswa bisa juga berkomunikasi dengan guru melalui fitur yanfg di sedikan di EDiscussion ini.

\section{Use Case Diagram}

Use case diagram merupakan diagram yang menampilkan interaksi antar aktor. Use Case diagram akan memberitahu apa saja yang akan di kerjakan oleh aktor terhadap sistem. Untuk lebih jelasnya dapat melihat gambar 2 ini

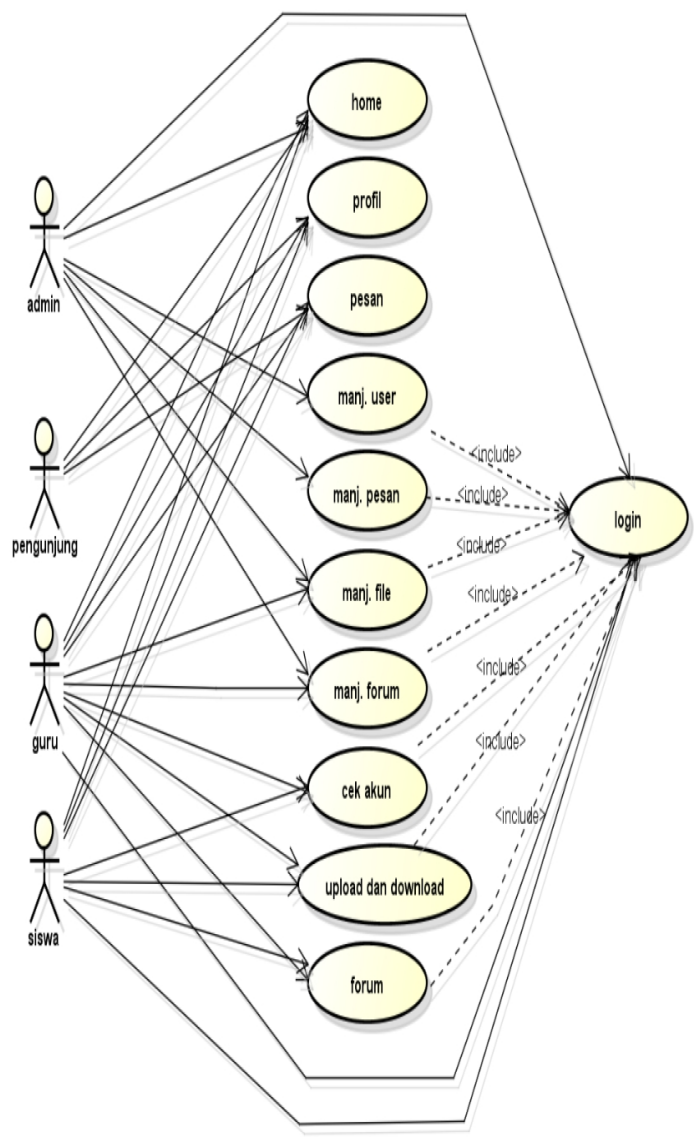

Gambar 2. Uses Diagram

\section{Class Diagram}

Class diagram merupakan class-class yang nantinya akan menjadi tabel-tabel yang kita butuhkan dalam pembuatan database. Class Diagram berfungsi menjelaskan objek yang

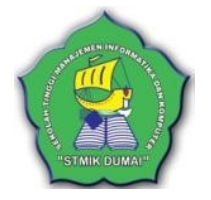

saling berhubungan/interkasi dalam sebuah model atau database.

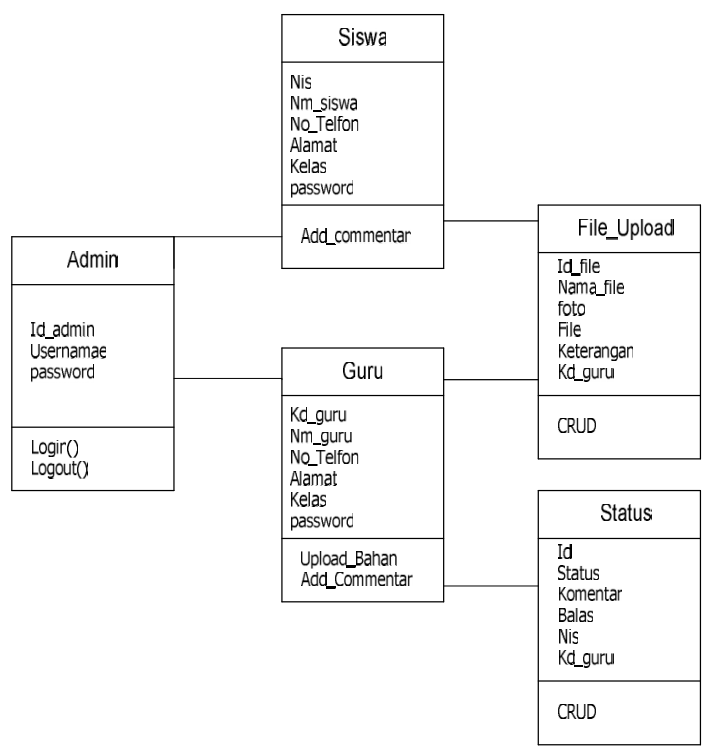

Gambar 3. Class Diagram

\section{Activit y Diagram}

Activity Diagram menjelaskan alur aktivitas aktor dalam sistem yang sedang dirancang. Setiap aktor yang terdapat dalam sistem yang sedang di rancang akan dijelaskan pekerjaan nya di dalam sistem informasi ini. Activity Diagram memberikan penjelasan kapan aktor akan memulai pekerjaan terhdap sistem dan kapan aktor ak:

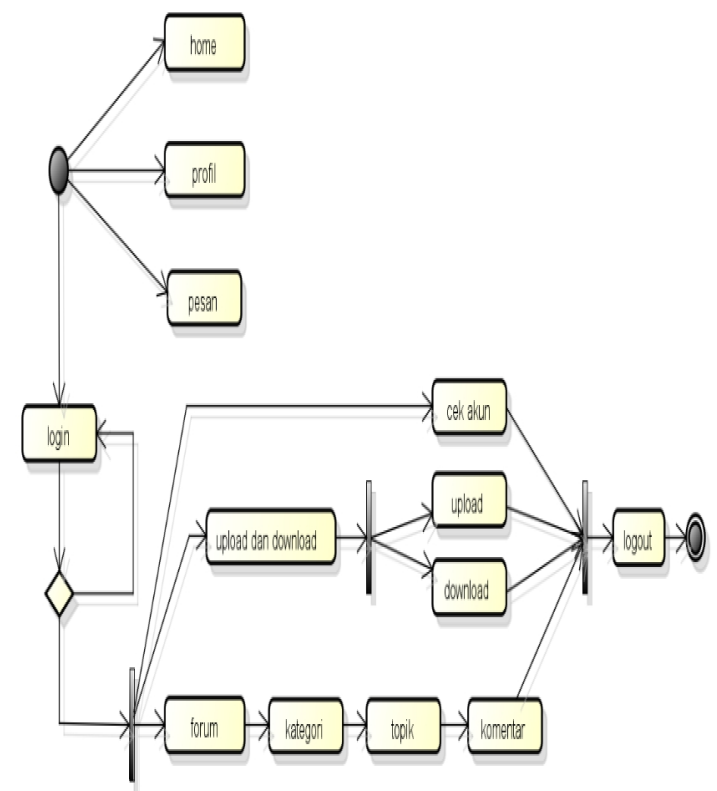

Gambar 4 Activity Diagram Admin 
I N F ORM A I I A

Jurnal Informatika, Manajemen dan Komputer, Vol. 12 No. 1, Mei 2020

elSSN : 2580-3042

pISSN : 1979-0694

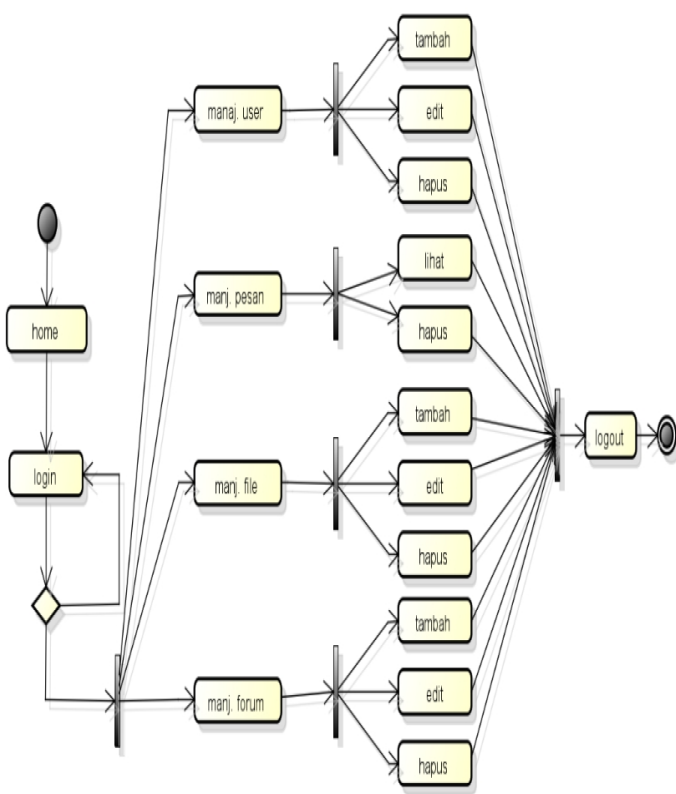

\section{Form Login}

Login merupakan sebuah tampilan untuk bisa masuk ke dalam sistem. Form login akan menampilkan username dan password yang sudah ada di dalam database.

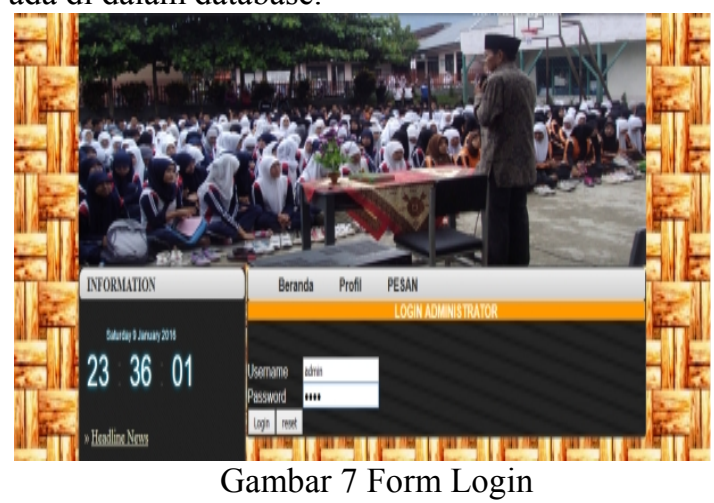

\section{Form Dashboard Admin}

Setelah admin sukses masuk ke dalam sistem melalui form login, maka akan tampila homepage

Gambar 5 Activity Diagram Login Siswa

\section{Deployment Program}

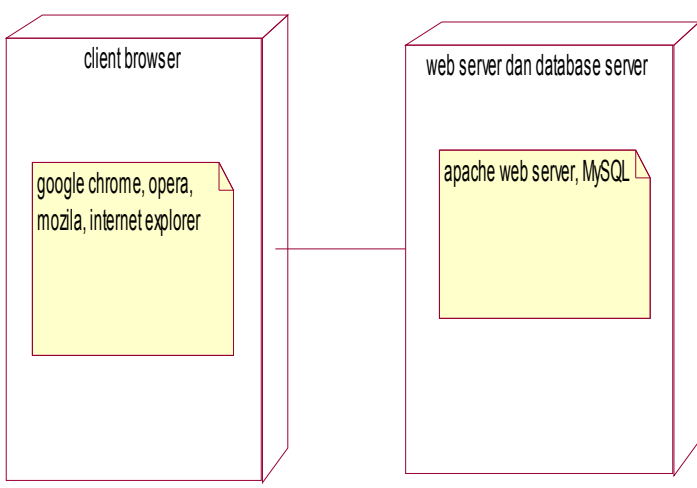

Gambar 6 Deployment Diagram

\section{Output Program}

\section{Menu Utama}

Menu Utama, akan tampil meu-menu terkait dengan sekolah, ini juga bertujuan memberi gambaran tentang profil, visi dan misi dari Sekolah.

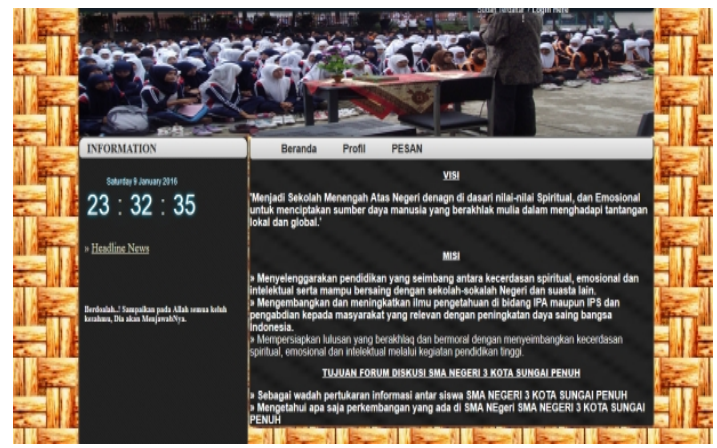

bagi admin.

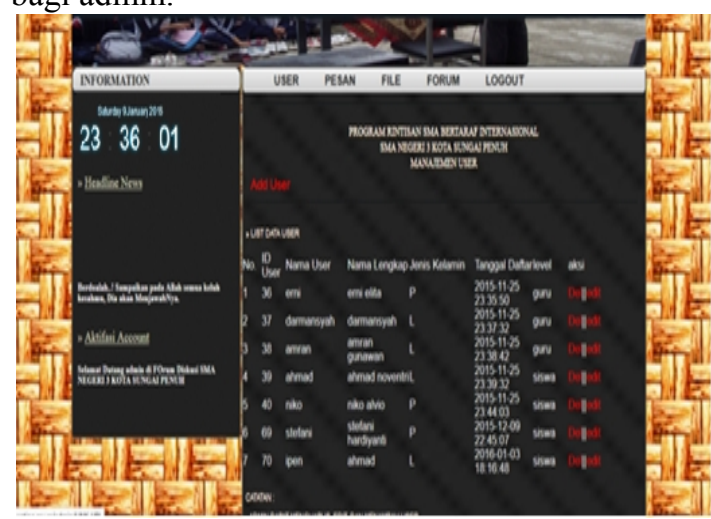

Gambar 8. Dashboard Admin

\section{Form Dashboard Guru}

Form Dashboard Guru berguna untuk upload data, download data dan memberikan data-data yang dibutuhkan oleh siswa.

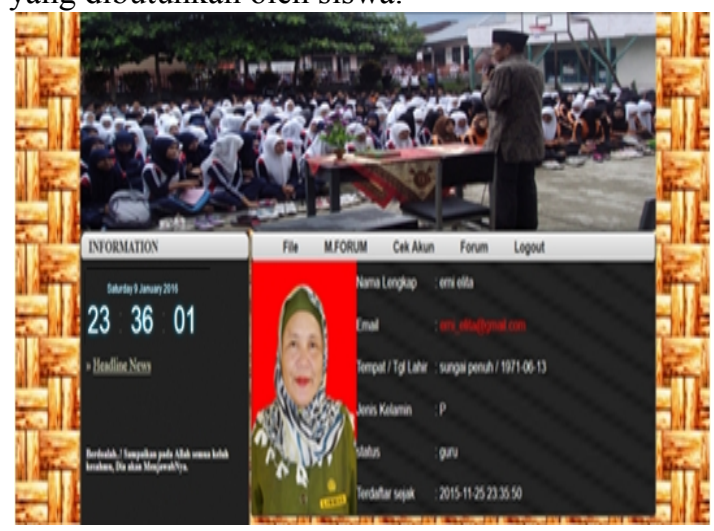

Gambar 9 Form Dashboar Guru

\section{Form Dashboard Siswa}

Melalui Form Dashboar siswa ini, siswa dapat berinteraksi melalui forum ini untuk melakukan 
IN F O R M A T I A

Jurnal Informatika, Manajemen dan Komputer, Vol. 12 No. 1, Mei 2020

elSSN : 2580-3042

pISSN : 1979-0694

tanya jawab dengan siwwa lain atau dengan guru melalui internet.

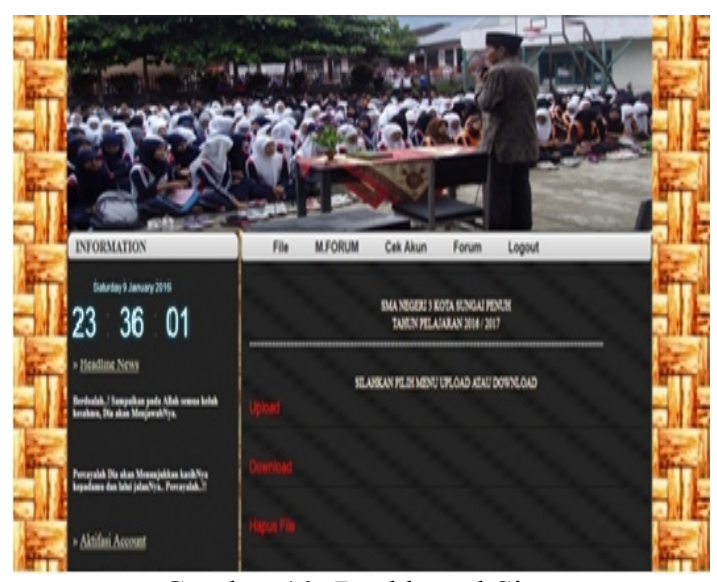

Gambar 10. Dashboard Siswa

\section{Form Dashboard Siswa}

Melalui Form Dashboar siswa ini, siswa dapat berinteraksi melalui forum ini untuk melakukan tanya jawab dengan siwwa lain atau dengan guru melalui internet.

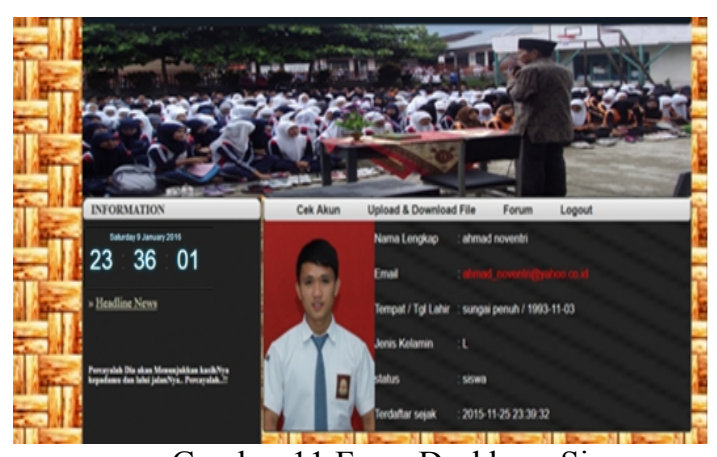

Gambar 11 Form Dashboar Siswa

\section{Form Diskusi}

Forum Diskusi berguna untuk menampilkan pembahasan yang di bahas anatar guru dengan siswa, atau siswa dengan siswa.

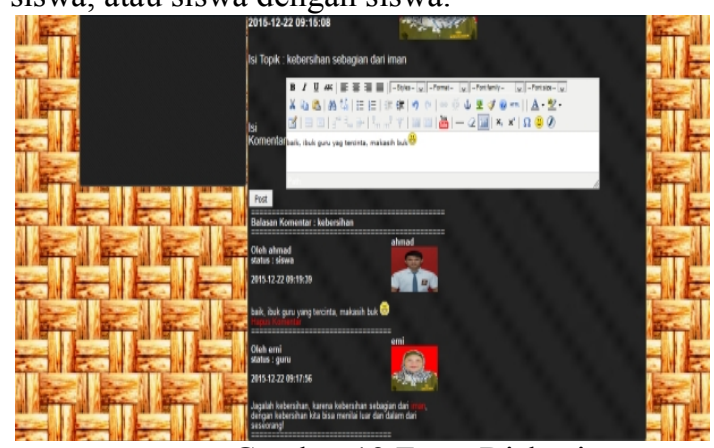

Gambar 12 Form Diskusi

\section{Form Komentar}

Form komentar akan aktif apabila ada siswa atau guru yang membuat sebuah pertanyaan di dalam forum diskusi ini.

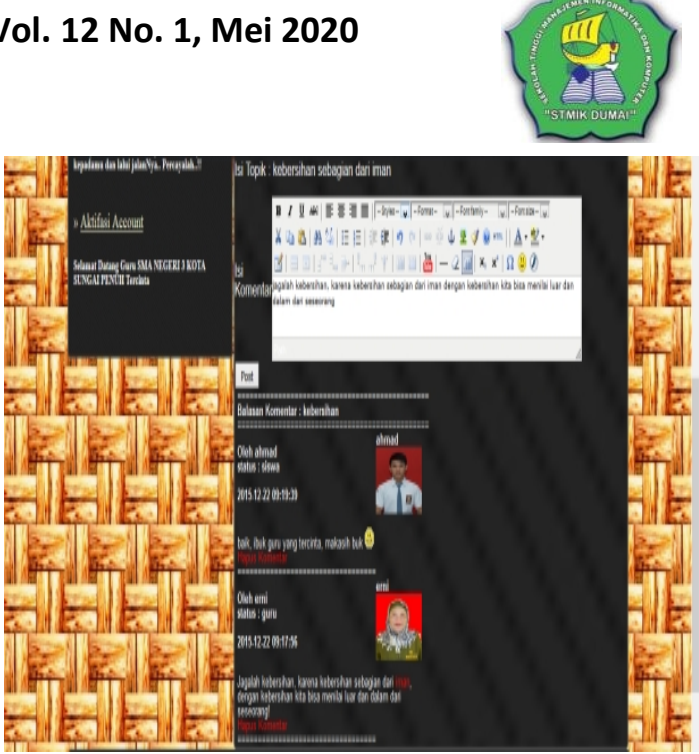

Gambar 13 Form Komentar

\section{KESIMPULAN}

E-Diskusi atara guru dan siswa adalah suatu media tanya jawab berbasis online yang digunakan untuk mempermudah guru dan siswa untuk saling berkomunikasi dimana guru dan siswa dapat berkomunikasi tanpa ada batas ruang dan waktu dengan adanya E-Diskusi guru dan siswa dapat bertukar informasi baik dengan cara mengupload file, download, melihat data guru maupun siswa, dan juga bisa melaukan proses Tanya jawab ataupun membahas sesuatu seputar sekolah. Dalam penerapan E-Diskusi dapat meningkatkan mutu peambelajaran di SMA NEGERI 1 TANAH MERAH, dengan meningkatnya mutu pembelajaran tersebut maka akan menghasilkan siswa yang mandiri dan berkualitas. Dengan adanya E-Diskusi proses pertukaran informasi menjadi lebih efisien dan efektif.

\section{REFERENSI}

Ranuharja, Fadli. (2017).Sistem Informasi EDiscussion Menggunakan Php.

Dewi, A. K. (2012). Perancangan Dan Implementasi E-Learning Berbasisweb Dengan Standarisasiworld Wide Web Consortium (Studi Kasus Sma N Karangpandan). Jurnal Informatika.

Lukitaningrum, H. (2016). Pengembangan Media Pembelajaran Berbasis Web Pada Materi Basis Data Di Sekolah Menengah Kejuruan Kelas Xi. 77.

Sinaga, B. (2015). Perancangan Dan Pembuatan Sistem Informasi Forum Diskusi Mahasiswa / I Berbasis Web Di Stmik Pelita Nusantara Medan. 18(2), 58-63.

Web, B., Sma, D. I., Bandung, B. P. I., \& Hamdan, D. D. (N.D.). Pembangunan Aplikasi ELearning Pelajaran Secara. (112). 